\title{
A new durability assessment methodology of thermal mortars applied in multilayer rendering systems
}

\author{
J. Maia ${ }^{(1)}{ }^{*}$, Nuno M. M. Ramos ${ }^{(1)}{ }^{*}$, R. Veiga ${ }^{(2)}$
}

(1) CONSTRUCT-LFC, Faculty of Engineering (FEUP), University of Porto, Porto, Portugal, Rua Dr. Roberto Frias s/n, 4200-465 Porto, Portugal.

${ }^{(2)}$ LNEC, National Laboratory for Civil Engineering, Lisbon, Portugal, Av. do Brasil 101, 1700-066 Lisbon, Portugal.

*Corresponding author:

E-mail: joanamaia@fe.up.pt, Tel: 00351225081262

\section{ABSTRACT}

The increase of the thermal resistance of building envelopes is a result from the growing demand of energy efficiency. Several new materials and systems emerged in recent years as an answer to that growing need. Thermal mortars applied in thermal rendering systems are an example of how the research community and the building industry try to tackle that challenge. A gap in the durability assessment of thermal rendering systems can however be observed. The existing standardization for the durability assessment of mortars does not allow a consistent evaluation of thermal mortars, especially in multilayer systems. As such, the main goal of the present work consists in proposing a durability assessment methodology of thermal mortars applied as multilayer systems. Accelerated ageing cycles, directly applicable to thermal mortars, were developed through numerical simulation, taking into account material properties, climatic conditions and consequent degradation mechanisms to which the system is subjected. A theoretical methodology for the determination of heat-cold cycles that can represent specific climatic conditions was developed. The implementation of the developed accelerated ageing 
cycles and the obtained experimental results contributed to the definition of a new durability assessment methodology. This methodology defines the accelerated ageing cycles that should be performed in each climate zone, representative of the main degradation mechanisms. One of the major advantages is the temperature adaption of the accelerated ageing cycles to the climatic conditions. The new methodology contributes to the evaluation of new solutions, during their development stage, and to their adequacy for specific climatic conditions.

\section{KEYWORDS: Thermal mortar, Durability, Accelerated ageing, Experimental tests,}

\section{Numerical simulation.}

\section{INTRODUCTION}

The application of new products and systems in building envelopes can contribute to a reduction of the building service life if there is a lack of technical knowledge. As such, the durability assessment of new materials and systems during the product development stage is of major interest. Durability consists of the "capability of a building or its parts to perform its required function over a specified period of time under the influence of the agents anticipated in service"[1] and could be affected not only material properties but also by environmental agents and specific in-service conditions [2]. The improvement of the durability of the materials and the increase of the service life of buildings is a step towards sustainability as it contributes to the lowering of waste production and to the reduction of the emission of polluting gases into the atmosphere [3].

The focus on the energy efficiency in European buildings [4] has led, among other measures, to the development of building envelopes with growing overall thermal resistance. As such, the reduction of the thermal conductivity of envelope materials is pursued by the 
industry. In the case of thermal insulating mortars, the manufacturers the attempt to lowering thermal conductivity and density (below $600 \mathrm{~kg} / \mathrm{m}^{3}$ ) [5]. The strategies to do so include using lightweight aggregates such as EPS [6, 7], cork [6-9] or aerogel [10,11] and matrixes of high porosity. Nevertheless, the lack of experience in their application can result in undesired early degradation, compromising the durability.

The durability of buildings in-service conditions is highly affected by environmental agents, material properties, design and corresponding detail, workmanship and maintenance [2]. Materials can react differently to the degradation agents that they are subjected to, being the selection of materials with properties that meet the durability requirements of great importance [12]. The knowledge of these parameters is obtained through existing data, which may not include all the relevant agents. In the case of new products, this knowledge does not exist. Consequently, the durability evaluation should be an important aspect in their development. The durability assessment of renders depends on the nature of the materials and the degradation mechanisms to which the materials are subjected to [13]. In general, the durability assessment could be carried out taking into account: (a) benchmark tests (usually accelerated ageing tests), (b) reference materials/comparative tests (used to calibrate the test equipment and the test materials and methodology, simulating the service environment by accelerating or intensifying the environmental factors), (c) environmental/stress testing and (d) site testing (natural exposure or "in situ" monitoring) [14].

According to Escobar and Meeker [15], "acceleration" is not a defined concept and could have various definitions. Accelerated testing can be expressed as "compress time and accelerate the failure mechanisms in a reasonable test period so that product reliability can be assessed" [16]. The acceleration could be performed through several methods, such as the increase of the rate of use and the level of stress of the testing equipment. Knowing that a large part of the 
materials is sensitive to more than one degradation mechanism, the combination of models should be applied. However, when the failure mechanisms are complex and have many variables the implementation of physical models, by extrapolation, may not be useful, since these models are applied for well-known mechanisms. When the degradation mechanisms are highly complex, the application of empirical acceleration models is more adequate since they use available data to evaluate the resulting deterioration [15]. The relevance of each degradation mechanism depends on the climate as well as on the building materials and correspondent behaviour to the climatic conditions. In general, it is difficult to simulate all the degradation mechanisms and the way they interact together. In fact, a great amount of research studies evaluate the effect of temperature and moisture to perform the long-term ageing of building materials, since they are relevant parameters in the degradation of mortars [17-19]. Daniotti, Spagnolo [20] developed a specific ageing cycle, considering the specific conditions of a material/system application (as defined in Guidance Document 3 [21]). However, owing the difficult to reproduce all the effects, the most representative cycle may be the assertive choice. The authors state that there exist three different ways of pre-designing ageing cycles: (a) through existing standards (existing hygrothermal tests could be assumed as the first hypothesis), (b) applying climatic data analysis (statistical analysis of existing climatic data combined with the determination of the main degradation mechanisms) and (c) developing a preliminary degradation model (based on a preliminary degradation simulation model) [22].

The EN 998-1 [23] standard provides durability evaluation (freeze-thaw action) according to the standard test method presented in EN 1015-21[24] but does not present any specific requirements regarding the durability of thermal mortars. In addition to the thermal mortar systems, there are other multilayer systems, such as the External Thermal Insulation Composite Systems (ETICS). Regarding ETICS, the durability assessment is defined in ETAG 004 [25], 
where hygrothermal and freeze-thawing ageing cycles are envisaged. Although existing standards provide a frame for thermal insulating mortars - EN 998-1 [23] -, the durability assessment of thermal mortars is not explored and no document refers to their application and evaluation as a multilayer system. As such, a durability assessment methodology directly applicable to thermal rendering systems does not exist, which highlights the need of its development. As observed, the durability assessment is commonly performed through accelerated ageing cycles that simulate specific climatic conditions. However, the climatic variability in Europe and the lack of validated ageing cycles, considering thermal rendering systems, emphasize the importance of developing specific accelerated ageing cycles taking into account those variables. Directing the durability evaluation to the desired performance will guarantee solutions that are more durable, raising the adequacy of this type of systems to the climate where they will be applied.

The objective of this article is to propose a durability assessment methodology applicable to thermal mortars applied as multilayer systems. The first part of the work consists on the development of accelerated ageing cycles, through numerical simulation, taking into account material properties and European climatic conditions. The second part presents the experimental results of implementing the developed accelerated ageing cycle, which contributes to the definition of the methodological process of the new durability assessment methodology. A general durability assessment methodology applicable to thermal rendering systems, taking into account material properties and specific climatic conditions, represented by the developed ageing cycles, will be presented (see Fig. 1).
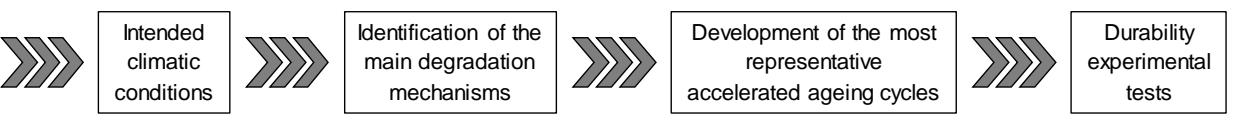

Fig. 1. Durability assessment methodology. 


\section{MATERIALS AND METHODS}

\subsection{Framework}

Regarding the durability assessment in the European context, the application of thermal rendering systems in such different climates should be taken carefully. As such, building envelopes (materials and systems) should be adapted to the environmental actions to which they will be subjected $[26,27]$ Since different degradation mechanisms may occur in different climates, an accurate adaptation of the accelerated ageing cycles (heat-cold, heat-rain and/or freeze-thawing cycles) is of the highest relevance. One of the most used climate classifications is Köppen-Geiger [28]. European climates are generally classified as warm temperate (C) and snow (D), excepting some regions in Spain that are arid (B). Portuguese climate is classified as warm temperate, summer dry and hot/warm summer (south/north of the country) [29]. The EOTA Guidance Document [21] presents a simpler approach to classify the European climates, according to the air temperature and the solar energy intensity. The European temperature subdivision is performed according to the winter and summer conditions, resulting in three temperature zones: Zone A (cold winters), Zone B (moderate winters) and Zone C (warm winters). As such, different agents and related degradation mechanisms may have a significant impact on façade systems, such as freeze-thawing, in higher latitude climates, and temperature fluctuations performed by heat-cold temperature variation. Regarding the air temperature and the UV radiation, a simple division into moderate and severe climate is also envisaged in the referred document. Severe climates, with higher solar exposition, may present a significant degradation in the façade systems due to the thermal shock in hot surfaces, caused by an abrupt decrease of temperature originated by cold rain incidence.

Regarding the interest in developing a durability assessment applicable to thermal rendering systems, it is important to cover a wide range of climates and, consequently, different 
degradation mechanisms. Their analysis highlighted the importance of taking into account representative accelerated ageing cycles of the different European climatic zones. As such, the durability assessment methodology comprises the development of hygrothermal ageing cycles through numerical simulation, which can be adapted to different European climates. The analysis of existing ageing procedures (such as the envisaged in EN 1015-21 and ETAG 004) combined with hygrothermal simulation led to the development of a new hygrothermal accelerated ageing cycle, consisting of heat-cold and heat-rain cycles.

\subsection{Materials}

A commercial thermal rendering system, already in use by the construction industry, was used as an example case in this work. Its adoption was intended for highlighting the applicability of the assessment methodology and to obtain practical results. The system is comprised of 3 main layers: thermal mortar (TR), finishing render (C) and two alternative finishing coatings (organic - O or mineral - M), which are described in Table 1.

Table 1. Constituent materials of the studied thermal rendering system

\begin{tabular}{|c|c|c|c|c|}
\hline Layer & Material & Binders & Aggregates & Layer properties \\
\hline $\begin{array}{l}\text { Thermal } \\
\text { mortar }\end{array}$ & $\mathrm{TR}$ & Lime & EPS & $\begin{array}{l}4+2 \mathrm{~cm} \text { (glass fibre mesh } \\
\text { between the layers) }\end{array}$ \\
\hline $\begin{array}{l}\text { Finishing } \\
\text { render }\end{array}$ & $\mathrm{C}$ & $\begin{array}{l}\text { Natural hydraulic lime, cement, } \\
\text { pozzolans and polymers }\end{array}$ & $\begin{array}{l}\text { Mineral fillers, synthetic } \\
\text { fibres and resins }\end{array}$ & $\begin{array}{l}\approx 4 \mathrm{~mm} \text { (glass fibre mesh } \\
\text { in the render) }\end{array}$ \\
\hline \multirow{2}{*}{$\begin{array}{l}\text { Finishing } \\
\text { coating }\end{array}$} & $\mathrm{O}$ & \multicolumn{2}{|c|}{$\begin{array}{l}\text { Mineral fillers, resins in aqueous dispersion, pigments, and } \\
\text { specific additives (antifungals and others) }\end{array}$} & \multirow{2}{*}{1 to $2 \mathrm{~mm}$} \\
\hline & M & Lime and hydraulic binder & $\begin{array}{l}\text { Mineral fillers, pigments, and } \\
\text { specific additives }\end{array}$ & \\
\hline
\end{tabular}

The thermal rendering system under study was used in the development and implementation of the accelerated ageing cycles, as shown in Fig. 2. 


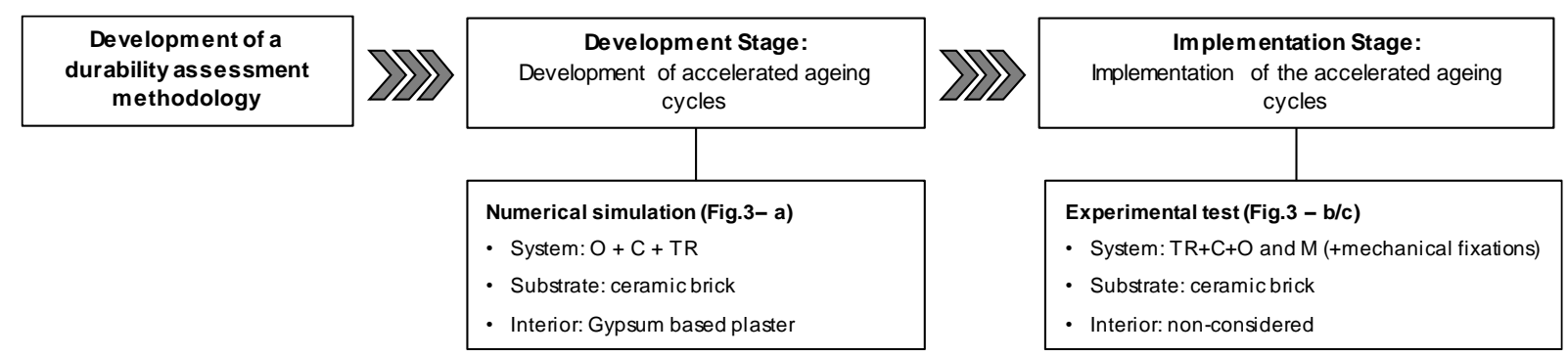

Fig. 2. Methodological process for the development of a durability assessment methodology applicable to thermal rendering systems

A ceramic brick masonry with a density of $650 \mathrm{~kg} / \mathrm{m}^{3}$ and a thermal conductivity of 0.13 $\left.\mathrm{W} /\left(\mathrm{m} \cdot{ }^{\circ} \mathrm{C}\right)\right)$ was used as substrate. An interior plaster was also considered in the numerical simulations (gypsum plaster with dry bulk density of $850 \mathrm{~kg} / \mathrm{m}^{3}$ and thermal conductivity of $\left.0.20 \mathrm{~W} /\left(\mathrm{m} \cdot{ }^{\circ} \mathrm{C}\right)\right)[30]$.

The configuration of the specimens used in the two different stages (development stage simulation and implementation stage - experimental) is shown in Fig. 3. The specimen for the implementation of the developed ageing cycle, was built in a test rig with $3 \times 2.5 \mathrm{~m}^{2}$ of testing surface. Two rectangular openings ( $0.40 \mathrm{~m}$ wide by $0.60 \mathrm{~m}$ high $)$, consisting of the absence of the thermal mortar on the substrate, were performed at the superior corners of the rig, positioned at $0.40 \mathrm{~m}$ from the edges (Fig. $3-\mathrm{b}$ ).

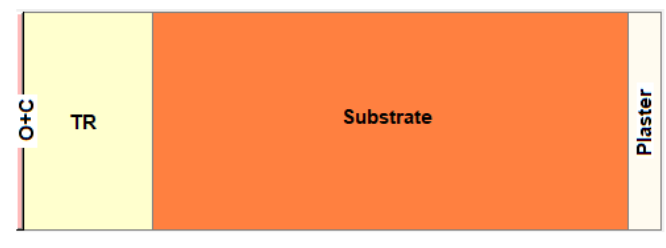

a)

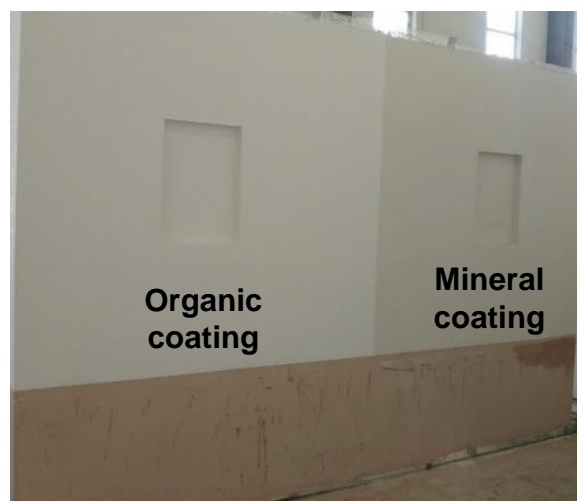

b)

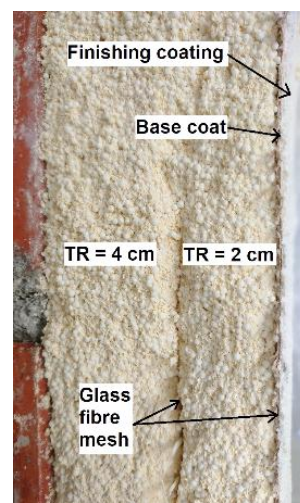

c)

Fig. 3. Specimen configuration used in the: a) Numerical simulation; b) Implementation face view; c) Implementation - Section/cut view. 


\subsection{Test methods}

The developed hygrothermal ageing cycles (presented in 3.1) were implemented in the test specimen presented in Fig. 3-b), in a climatic chamber Aralab Climatest Fitoclima 700 EDTU, available in the Portuguese National Laboratory for Civil Engineering (LNEC).

To evaluate the durability of the thermal rendering systems, several experimental tests were performed, before and after the ageing cycles. The liquid water permeability was determined with the Karsten tubes method measuring the absorbed water volume after 5, 10, 15, 20, 25, 30, 40, 60 and $120 \mathrm{~min}$ [31]. After bonding 3 tubes $(10 \mathrm{ml})$ to the rendered surface, each tube is filled with water and the drop in the water level is recorded. The dynamic elastic modulus was determined by a non-destructive test, measuring the fundamental resonance frequency. The EN 14146 [32] method was applied using the ZRM Zeus 2005 equipment, at LNEC. The fundamental resonance frequency is recorded after instantaneous excitation of the specimen. The adhesive strength test is performed based on the EN 1015-12 [33]. Five circular pre-cuts were performed, using a core drilling machine and the test using a dynamometer CONTROLS C 215/D with manometer with a scale 0 to $5 \mathrm{kN}$ with resolution of $50 \mathrm{~N}$. The resistance to impact test was based on EN13497 [34], using the Martinet Baronnie apparatus.

\section{ACCELERATED AGEING CYCLES}

\subsection{New accelerated ageing hygrothermal cycle}

The development of accelerated ageing cycles adapted to thermal rendering systems, which replicate certain climate conditions, is the most relevant task in the present study. The combination of the three methods presented by Daniotti, Spagnolo [20], was the base for the development of the heat-cold cycle, applied to thermal rendering systems:

- Climatic data: using existing climatic data files and "in situ" measurements; 
- Existing standards: based on EN 1015-21 and ETAG 004, applied to mortars and ETICS, respectively;

- Preliminary degradation model: dynamic numerical simulation of the most representative degradation mechanisms.

The principle consists in combining the effect of temperature variation and water action in two distinct ways:

- High-temperature variation: heat-cold cycles;

- Thermal shock: abrupt decrease of a warm façade by cold rain.

The durability assessment of the thermal rendering systems is presented with an example focused on the South European climate context. In that way, a severe Portuguese climate was selected, presenting a high-temperature variation with cold winters and warm summers. Therefore, the city of Bragança, located in the interior Northeast of Portugal, fitted the requirements, classified as Csa according to Köppen-Geiger world climate classification [35].

The heat-cold ageing cycle was developed through numerical simulation, using the hygrothermal simulation tool WUFI Pro [30]. To maximize the temperature variation, the wall was modelled considering a high solar absorption coefficient $(\alpha=0.8)$ and the orientation with high solar radiation incidence (southwest orientation in the studied case). In addition, the rain incidence was not considered. The adopted methodology for the definition of the heat-cold cycle is presented in Fig. 4. 


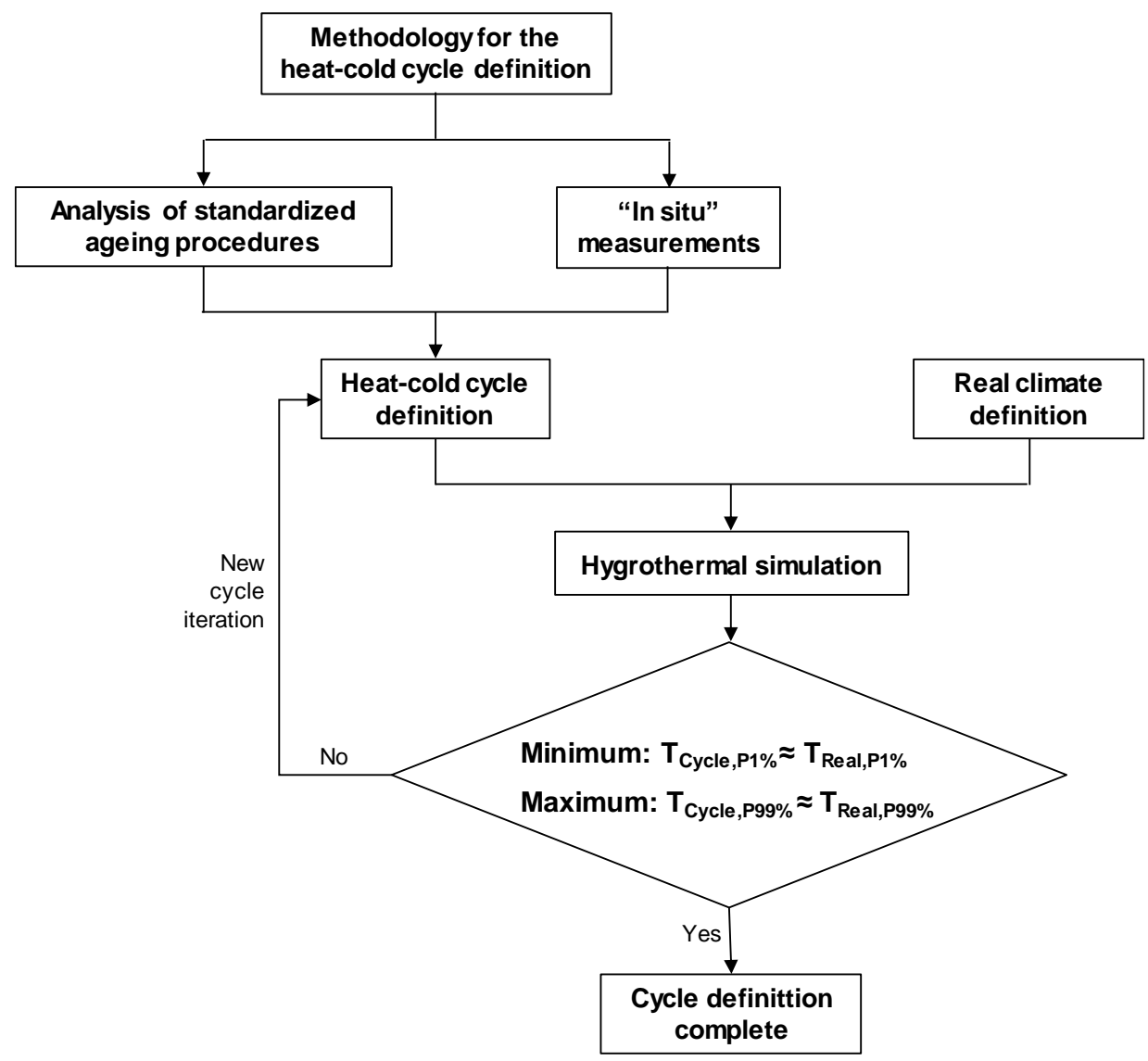

Fig. 4. Adopted methodology for the definition of the heat-cold cycle.

A different climatic action implies a different exterior surface temperature and, consequently, a distinct variation across the wall, as shown in Fig. 5.

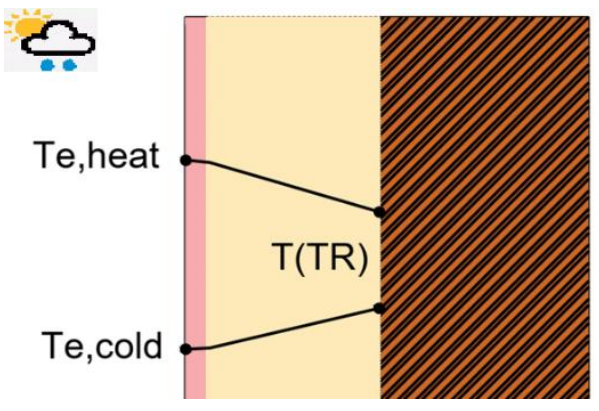

Fig. 5. Temperature variation across the wall due to a specific climatic action.

The effect of temperature variation across the wall, with special emphasis in the thermal render layer, was studied. As such, being the thermal render layer the main research subject, 
the cycle is defined by the comparison of the obtained temperature, in the thermal render layer $-\mathrm{T}(\mathrm{TR})$ - in both the simulated real climate and the heat-cold cycle. Two temperature indicators were chosen: the $1^{\text {st }}$ percentile, which is a representative value of the cold period (winter season), and the $99^{\text {th }}$ percentile, which is a representative value of the warm period (summer season). When simultaneously the minimum temperature value of the $1^{\text {st }}$ percentile and the maximum temperature value of the $99^{\text {th }}$ percentile in the cycle and in the real climate are similar, the cycle is fixed (see Fig. 6-a)). The temperatures and respective duration were adjusted, by an iteration process, to fit the requirements for the definition of the heat-cold cycle.

The heat-rain (HR) ageing cycle was developed through the combination of the heat-rain cycle, included in ETAG 004, and the "in situ" temperature measurements, determined in Sá [36]. The maximum temperature was adapted taking into account the "in situ" measurements and the duration of each heat and rain periods, as well as the number of cycles, were defined based on the ETAG 004 heat-rain cycle (see Fig. 6-b)). The cycle is repeated 80 times, comprising 20 days of ageing.

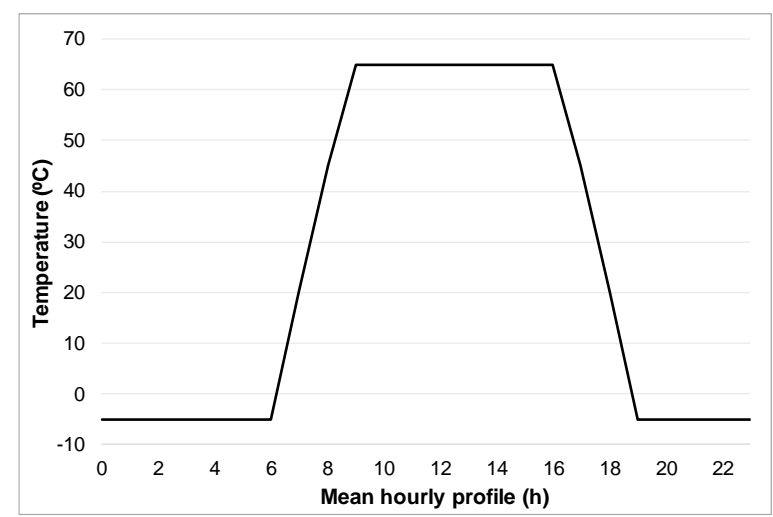

a)

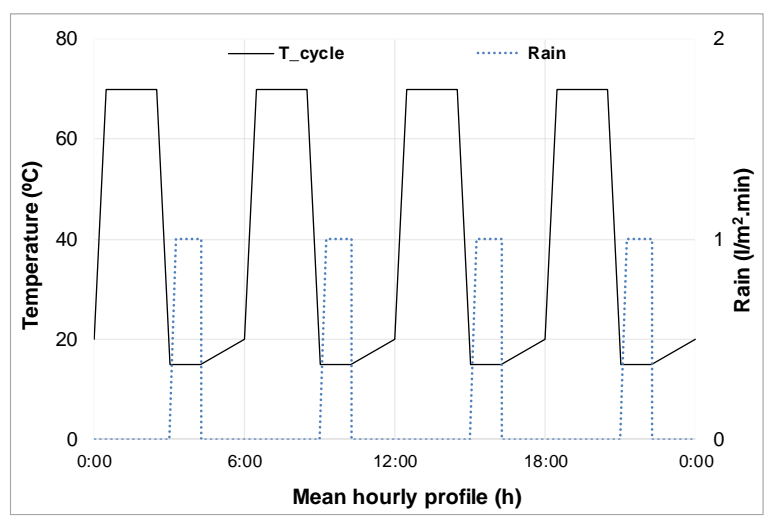

b)

Fig. 6. Hygrothermal ageing cycle: a) Heat-cold cycle; b) Heat-rain cycle. 
3.2. Theoretical methodology for the definition of heat-cold ageing cycles in Europe

Each heat-cold cycle could be obtained knowing two exterior air temperature indicators: $1^{\text {st }}$ percentile, of the winter period (December to February), and $99^{\text {th }}$ percentile, of the summer period (June to August) since they are more representative of extreme temperatures that occur more often. Since the climatic data should be representative of the climatic action, Test Reference Year climatic files should be used [37]. Each period has a theoretical linear regression, which gives the cold and heat cycle temperatures.

To obtain the theoretical linear regressions that represent the European climatic variability, 22 different European climates (referred as Group A) were chosen (see yellow markers in Fig. 9-a)). In addition, the climatic data were all in the database of the WUFI Pro software.

The WUFI Pro software was used to simulate the effect of one year exposure of the thermal render layer, in each of the 22 climates. The already referred temperature indicators were determined for the thermal render layer considering each climate and then compared to the obtained with the heat-cold cycle. The stop criterion is the same as the used in the previous subchapter 3.1 presented in Fig. 4: the similarity of the temperature in the thermal render between the climate and the cycle simulations. The cycle configuration, such as the duration of the heat and the cold periods and the ramp time, is the same. To obtain a robust theoretical regression the similarity was defined as less than $5 \%$ of the variation between the obtained temperature with each of the 22 climates and the respective cycle. Fig. 7 presents a schematic representation of the methodology used to develop the theoretical regressions.

The temperature indicators variation of the 22 real climates, used to define the heat and cold cycle temperatures considering the real climate and the heat-cycle, are lower or equal to 5\%, which were considered as a very good approximation, due to the temperature differences. 


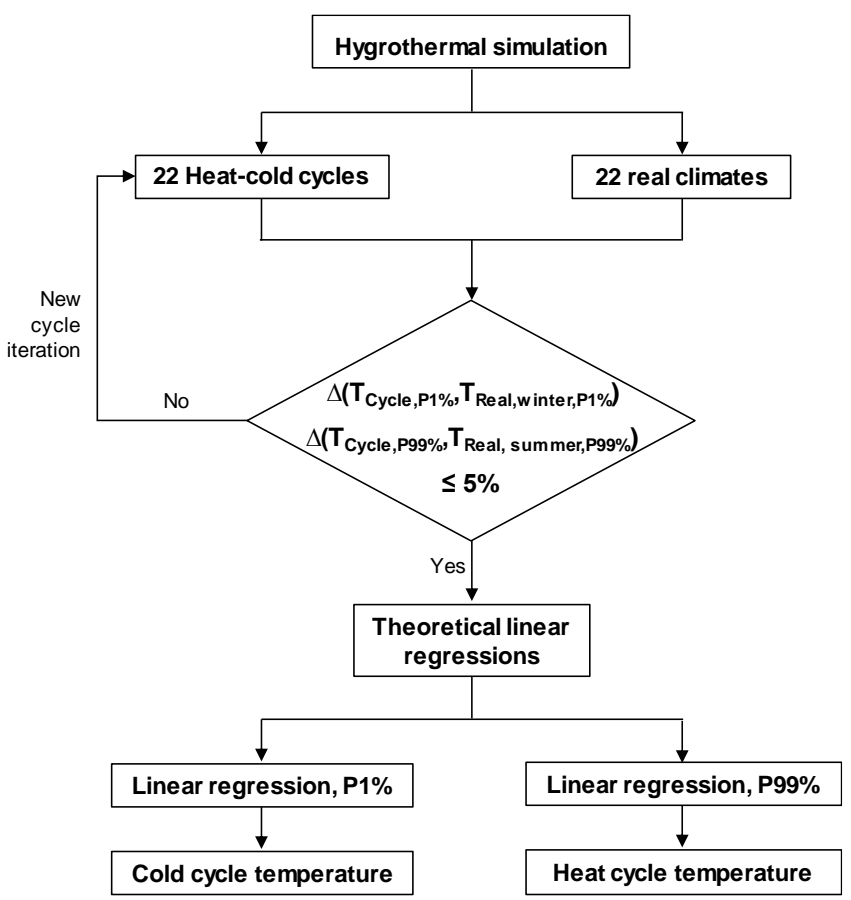

Fig. 7. Methodology for the definition of the theoretical algorithm for the heat and cold cycles temperatures determination.

Plotting the $1^{\text {st }}$ and $99^{\text {th }}$ percentiles of the exterior temperatures - real climate as a function of the cycle - two linear regressions for each cold $\left(1^{\text {st }}\right.$ percentile) and heat $\left(99^{\text {th }}\right.$ percentile) periods are determined, as shown in Fig. 8.

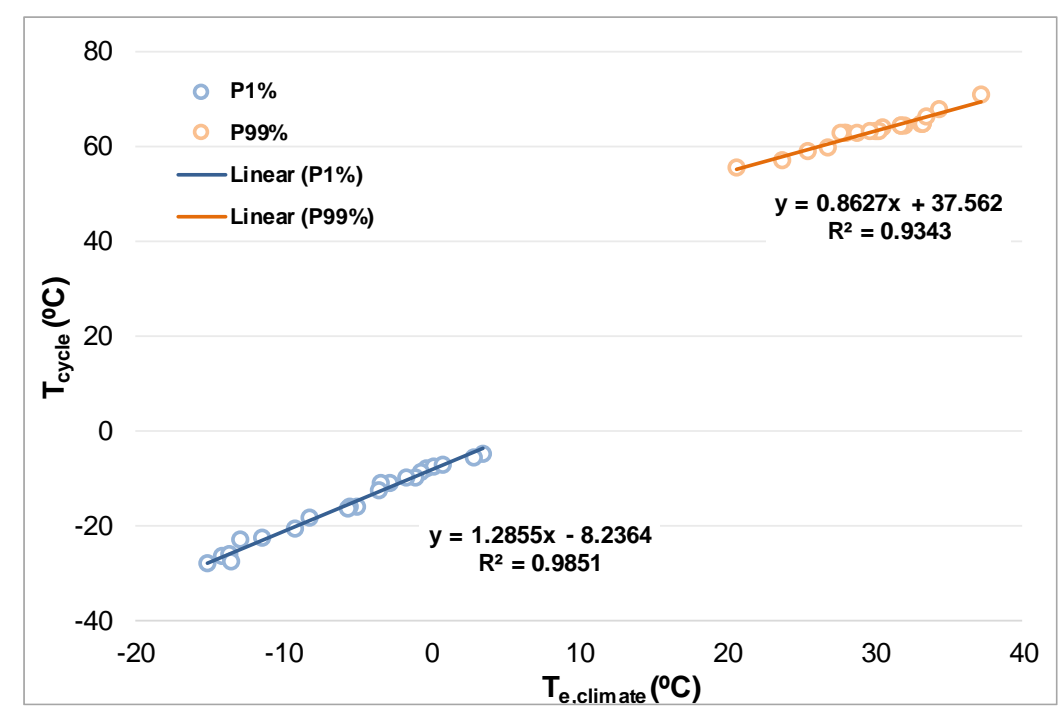

Fig. 8. Theoretical linear regressions for the heat-cold cycles determination. 
Therefore, to define each temperature for the cold and heat periods, the equations (1) and (2) are used.

$$
\begin{gathered}
T_{\text {cycle }}(\text { cold })=1.2855 \times T_{e, P 1 \%}-8.2364 \\
T_{\text {cycle }}(\text { heat })=0.8627 \times T_{e, P 99 \%}+37.562
\end{gathered}
$$

This allows determining any heat-cold cycle from the knowledge of the two temperature indicators $T_{e, P 1 \%}$ and $T_{e, P 99 \%}$ of a real climate.

To validate the developed methodology, other 20 European climates (referred as Group B) were chosen to implement the theoretical regressions, as shown in Fig. 9-b) by the yellow markers. The choice of the 22 climates is linked to the available data files in WUFI Pro.

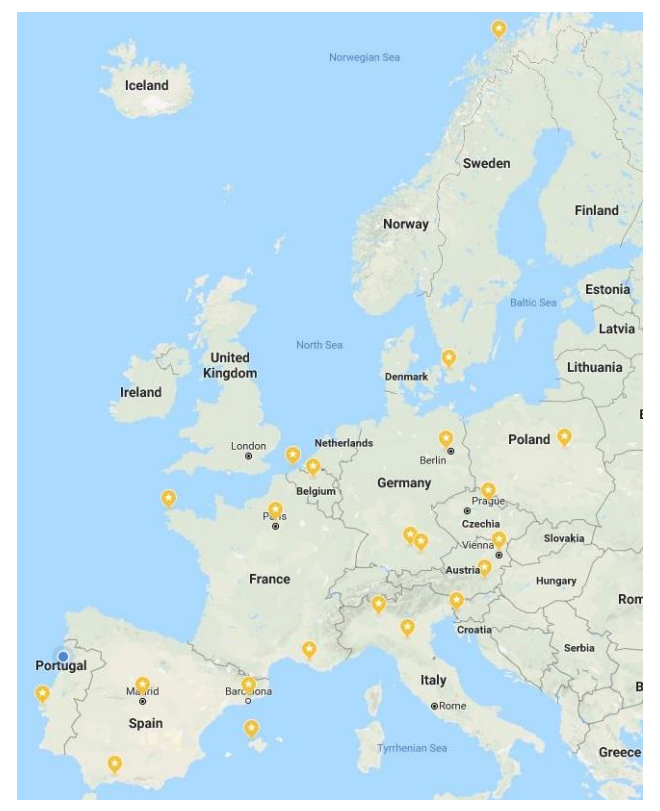

a)

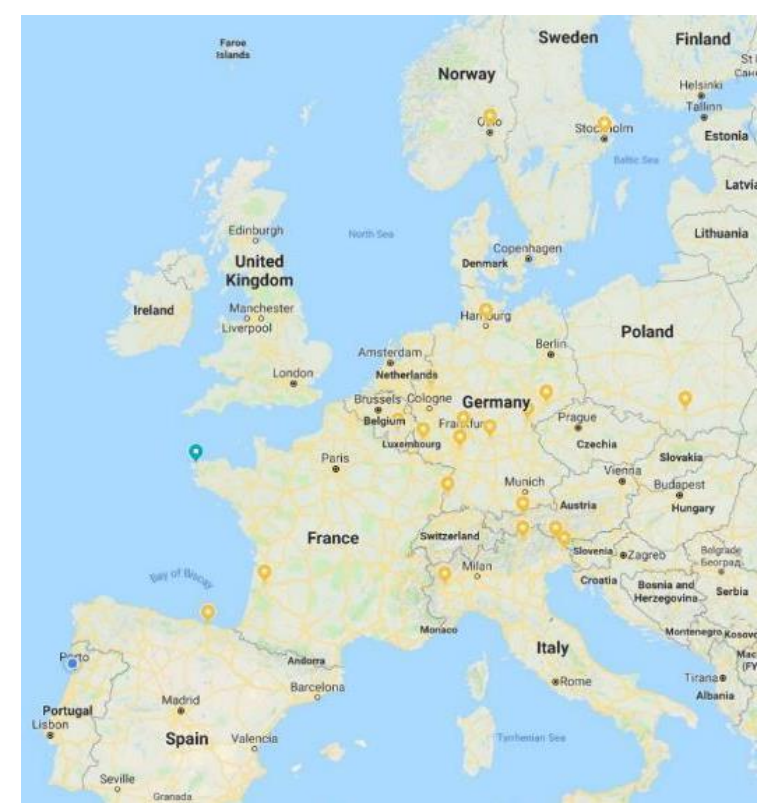

b)

Fig. 9. European climates distribution used in the theoretical linear regressions for the heatcold cycles determination: a) Definition - Group A; b) Validation - Group B. 
The validation was performed using the inverse methodology used in the definition process, described in Fig. 7. Each theoretical heat-cold cycle was simulated and the thermal render temperature compared to the one obtained with the real climate. If the temperature differences between the real climate and the theoretical cycle are less than $10 \%$ the methodology is validated. The percentages were defined regarding the observed residual temperature differences. The variation of the temperature indicators of the 20 real climates used to validate the heat and cold cycle temperatures, determined by equations (1) and (2), using the theoretical linear regressions, are lower or equal to $10 \%$. This was considered as a very good approximation, due to the low temperature differences. An average temperature variation of $6 \%$ and $4 \%$ in the cold and heat periods were obtained, respectively, which corresponds to $0.2{ }^{\circ} \mathrm{C}$ and $1.3^{\circ} \mathrm{C}$.

In summary, the developed methodology contributes to increment the knowledge on the thermal rendering systems, especially regarding their durability performance. In addition, the obtained results may contribute to the development of durability assessment methodologies applicable to thermal rendering systems, enhanced by the possibility of adaption of the analysis to each climatic zone.

\section{RESULTS OF THE IMPLEMENTATION OF THE NEW HYGROTHERMAL AGEING CYCLE}

The new hygrothermal ageing cycle (presented in Fig. 6), developed in 3.1, was implemented on the test specimen presented in Fig. 3. The experimental results obtained in the different tests, before and after ageing, are shown in Table 2. 
Table 2. Summary of the obtained experimental results.

\begin{tabular}{ccccccc}
\hline \multirow{2}{*}{$\begin{array}{c}\text { Impact } \\
\text { energy }\end{array}$} & Coating & $\begin{array}{c}\text { Liq. water } \\
\text { permeability } \\
(\text { after } 2 \mathrm{~h}) \\
{\left[\mathrm{ml} / \mathrm{m}^{2}\right]}\end{array}$ & $\begin{array}{c}\text { Dynamic } \\
\text { modulus } \\
(\mathrm{TR})[\mathrm{MPa}]\end{array}$ & $\begin{array}{c}\text { Dynamic } \\
\text { modulus }(\mathrm{C}) \\
{[\mathrm{MPa}]}\end{array}$ & $\begin{array}{c}\text { Adhesive } \\
\text { strength } \\
{[\mathrm{MPa}]}\end{array}$ & $\begin{array}{c}\text { Hard body } \\
\text { impact }(10 \mathrm{~J})\end{array}$ \\
\hline $\begin{array}{c}\text { Before } \\
\text { ageing }\end{array}$ & Mineral & 334.8 & 103.5 & 3820.6 & 0.08 & $\begin{array}{c}\text { Rendering } \\
\text { perforation }\end{array}$ \\
\cline { 2 - 7 } & Organic & 141.5 & 103.5 & 3820.6 & 0.07 & $\begin{array}{c}\text { Rendering } \\
\text { perforation; } \\
\text { delamination }\end{array}$ \\
\hline $\begin{array}{c}\text { After } \\
\text { HC+HR }\end{array}$ & Mineral & 749.8 & 393.0 & 2573.2 & 0.09 & $\begin{array}{c}\text { Rendering } \\
\text { perforation }\end{array}$ \\
\hline
\end{tabular}

The liquid water permeability is presented by the volume of absorbed water in the two coatings before and after the hygrothermal ageing cycles, as shown in Fig. 10.

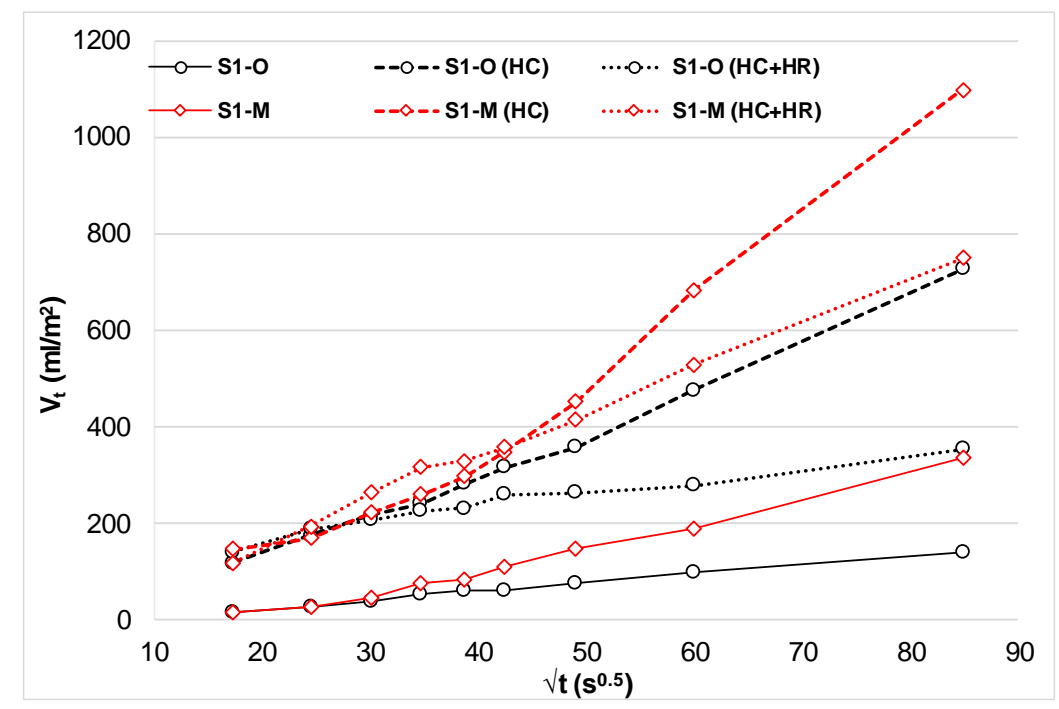

Fig. 10. Water permeability test results, before and after the hygrothermal cycles $(\mathrm{HC}+\mathrm{HR})$, using the Karsten tubes method.

As it can be seen, in the studied case, the mineral coating presented, in every stage, a higher water volume and absorption rate than the organic coating. Comparing the two ageing procedures, after the heat-cold ageing the two coatings presented higher absorption than after the heat-rain cycle. The heat-cold cycles promoted high-temperature variation, which may have resulted in the rupture of the materials (such as, cracks in the coating and the capillary net 
expansion by rupture of air voids), enabling the water to easily penetrate in the system. The reduction of the water absorption after $\mathrm{HC}+\mathrm{HR}$, comparing to after $\mathrm{HC}$, may be related to incomplete drying of the wall.

In terms of mechanical strength, with both coatings, the dynamic modulus increases after ageing, which means that the thermal render becomes more rigid, due to the strengthening and also to the late hydration of the binder. After ageing, the thermal render with the mineral coating presents a dynamic modulus $62 \%$ higher than the thermal render with the organic coating, resulting from the higher water absorption due to higher microcracking rate. The lower the dynamic modulus the higher elasticity and capacity of the material to absorb dimensional variations. Becoming the thermal render with mineral coating less flexible, the stresses increase and consequent cracking occurs. In fact, the lower elastic modulus presents greater advantages if the mechanical strength is not compromised. Regarding the adhesive strength, the ruptures were cohesive inside the thermal render, with the exception of one specimen using the mineral coating, where a deficient curing of the glue was observed. Regarding the ETAG 004 requirements, the thermal render fits the adhesion requirements. Despite the low values $(\leq 0.08$ MPa in most of the cases), the test results are considered acceptable, due to the cohesive rupture inside the thermal render. The embrittlement of the thermal render in the mineral coating system contributes to the considerable reduction of the adhesive strength, due to the rupture of some specimens during the attachment of the test machine. In contrast, the organic coating allows a lower variation of the adhesive strength, which may indicate that the materials keep their properties during more time. However, these coatings present higher degradation to UV radiation action. Regarding the impact resistance, the organic coating results in larger cracks and complete perforation (being the finishing render visible), especially with $10 \mathrm{~J}$ energy impact, while the mineral coating does not allow perforation, resulting in microcracks. However, higher 
depressions, detachment and loss of material are observed in the mineral coating. The application of the exterior coatings, both mineral and organic, allow the increase of impact resistance. Nevertheless, the performance is still limited, corresponding to category III defined in ETAG 004.

The simulated temperature matches the monitored temperatures in the organic coating, with a variation of $0.9 \%$ between the simulated and the measured average temperatures and amplitude of $1.2 \%$. Regarding the water content in the thermal render, the maximum obtained value in the simulation is of $11.3 \mathrm{~kg} / \mathrm{m}^{3}$ and the measured after ageing is of $12.0 \mathrm{~kg} / \mathrm{m}^{3}$, which corresponds to a variation of $6.3 \%$, but very similar in absolute value. Since the liquid water transport is more difficult to simulate, comparing to the surface temperatures, the obtained variation is acceptable.

\section{DEFINITION OF A DURABILITY ASSESSMENT METHODOLOGY APPLICABLE TO THERMAL RENDERING SYSTEMS}

The characteristics and durability of thermal rendering systems, suitable for exterior application, were highly explored in the present work. In that way, the paths to evaluate that type of systems are schematically presented in Fig. 11.

The methodology was developed taking into account the existing requirements presented in standards or guides, such as EN 998-1 and ETAG 004, and also in the experimental and simulation obtained results [38]. First of all, specific criteria regarding the material properties were defined in order to enhance the performance of the thermal rendering system.

As the trend on the development of new materials is in the lowering of the thermal conductivity of the thermal renders, the methodology is applicable to thermal renders with low thermal conductivity (less than or equal to $0.1 \mathrm{~W} / \mathrm{m} .{ }^{\circ} \mathrm{C}-\mathrm{T} 1$ classification) [23]. Beyond the 
thermal conductivity, the water vapour permeability resistance factor should be less than 15 [23] and the dynamic modulus less than $500 \mathrm{MPa}$, which were obtained in the experimental campaign in lightweight thermal renders (with EPS addition). The higher water vapour permeability of thermal renders allows better compatibility to ancient materials, comparing to ETICS, without compromising the thermal performance. The lower dynamic modulus also allows the absorption of higher displacements resulting in better compatibility with rigid substrates. Beyond the thermal render requirements, the establishing of finishing renders with low capillary absorption is of great importance, since the durability assessment is performed to the system as a whole that has to present an acceptable behaviour for exterior application.

One of the most important steps is the definition of climate conditions where the system is intended to be applied. Since the same thermal rendering system presents different deterioration to different degradation mechanisms, a material suitable for the application in a specific climate zone may not be suitable for a different location. The climate zones were divided according to the classification of EOTA Guidance Document 003 [21]. In that way, to optimize the durability assessment, different ageing procedures were associated to each climatic zone, regarding the collected knowledge of the implementation of durability methodologies, combining the existing procedures with the developed hygrothermal cycles. Since freeze-thawing is a severe degradation mechanism which implies a high deterioration of the system, despite the low water absorption of the coating, its evaluation in cold climates is of great importance. In addition, due to the ability of the thermal render to retain water, even in moderate climates, where the evaporation process is faster than in cold climates, the water may remain longer and be subjected to freezing conditions. The ageing procedures (freezing and thawing temperature, duration and number of cycles) should be the same as the described in the ETAG 004 (EOTA 2013), for small-size samples. 
Regarding the heat-cold cycles, each heat and cold temperatures can be adapted to the climate conditions where the systems are intended to be applied. The specimen may have the same configuration as the rig preconized in the ETAG 004. Implementing the logic of development of the heat-cold cycle presented in 3.1, the heat-cold cycle can be defined specifically to different European climates, as it is shown in 3.2.

The heat-rain cycle is intended to be applied after the heat-cold cycle in the same specimen. The heating temperature should also be adapted to the maximum reached temperatures, considering a worst-case scenario (high solar radiation incidence, high solar absorption of the coating), obtained by hygrothermal simulation or "in-situ" measurements. Considering warm climates, an accurate definition of the heating temperature is of great importance, since the thermal shock could increase and present higher detrimental consequences in the systems than in colder climates. When the durability assessment methodology were applied to synthetic coatings, the heat-rain cycles should be performed using UV radiation during the heating procedure, considering Zone $\mathrm{C}$ (warm climates). This is due to the higher degradation of these specific coatings to solar radiation action, which is particularly severe in warm climates emphasized by thermal shock due to rain action [39, 40]. The application of the referred coatings in warm climates, especially in Zone $\mathrm{C}$ climates requires the durability evaluation to UV radiation. However, the study of the UV radiation action in thermal rendering systems requires further developments.

Regarding the experimental tests to evaluate the durability, a visual inspection and the determination of the ultrasonic pulse velocity (in different areas of the specimen) for the detection of cracks in the coating is required. The ultrasonic pulse velocity should be determined by the ratio between the path crossed by the ultrasound wave and the time it took to perform it $[41,42]$. A fall of the ultrasonic pulse velocity reveals possible cracks. Cracking 
of the coating in the current zone is not admissible, since it demonstrates the weakness of the system in areas without higher concentration of stresses, allowing the water penetration in the entire system. In this case, the system should be classified as non-admissible for the tested climate zone. If no cracks are detected or if they occurred in areas with higher concentration of stresses and have less or equal to $0.2 \mathrm{~mm}$ thickness, the durability evaluation should continue and the water permeability, elastic modulus, adhesive strength and impact resistance are determined.

The liquid water permeability should be performed using the Karsten tubes method. This test allows the comparison of the absorbed water volume by the system in a vertical position. In addition, a simple setup is required, allowing quicker results. This method approximately describes some natural actions, such as the incidence of rain with strong winds. Three different tubes should be placed in different current areas, without cracks. The average values should be plotted and the slope of the resulting linear regression evaluated. A slope bigger than five times the initial slope (before ageing) is considered as potentially harmful, since it reveals that the water absorption rate increases very fast, regarding the obtained results.

The elastic modulus compatibility between the thermal and finishing render is of major importance, since high $E_{d}(C) / E_{d}(T R)$ ratio results in high stresses. As such, samples should be collected and the dynamic elastic modulus determined by the fundamental resonance frequency method based on EN 14146 [32]. The adhesive strength should be determined based on EN 1015-12 [33], using square pull-heads. In order to evaluate the adherence of the thermal render to the substrate and to the finishing render two different pre-cuts should be performed. The determination of the adhesive strength between the thermal render and the substrate implies five square pre-cuts until the substrate and between the thermal render and finishing render five square pre-cuts into the thermal render. The average value of each analysis should be registered. 
Since the thermal renders present in general a lower adhesive strength than current renders, low values are acceptable if the ruptures are cohesive in the thermal render itself since it means that the adhesive strength is greater than the test value. The impact resistance should be tested according to the procedures defined in EN13497 [34], using the Martinet-Baronie apparatus, since it allows the test in a vertical position. The $3 \mathrm{~J}$ and $10 \mathrm{~J}$ impact energies should be tested and the results are acceptable if the finishing render is not penetrated by either of impact energies.

The referred experimental tests are required both before and after the ageing action. These properties should not present high variation before and after ageing, in order to have a stable performance. The $E_{d}(C) / E_{d}(T R)$ ratio is also recommended to be lower than 40 , the adhesive strength bigger than $0.08 \mathrm{MPa}$ and the finishing render not penetrated, even before ageing.

The developed durability assessment methodology may not be applicable to all the thermal rendering and plastering systems since the materials should present threshold values regarding the defined properties (as observed in Fig. 11), but cover a wide range of thermal rendering solutions and can be extrapolated to other systems with further developments. 



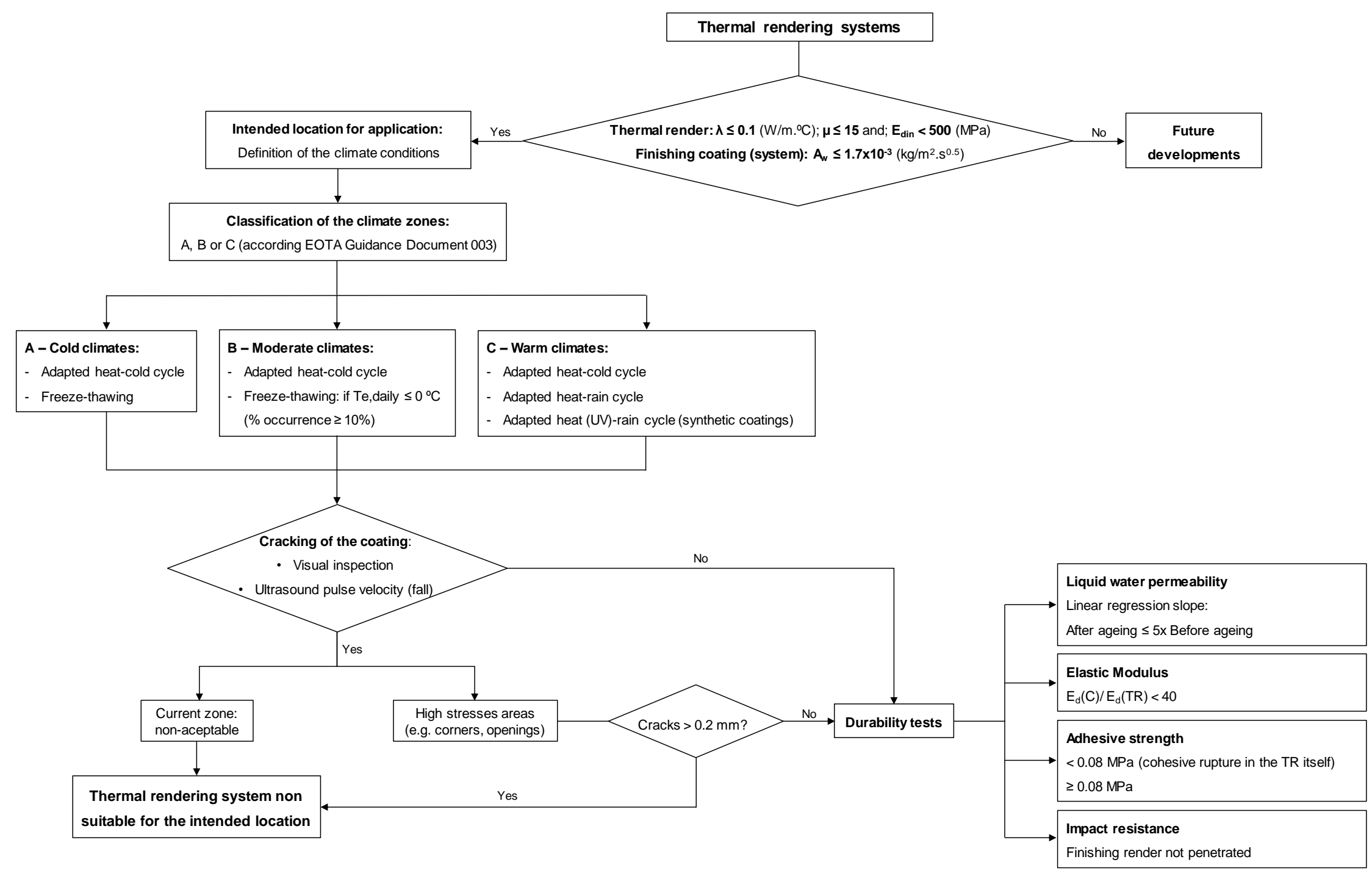

Fig. 11. Durability assessment methodology applicable to thermal rendering systems for exterior application. 


\section{CONCLUSIONS}

The prior knowledge in the durability assessment of thermal rendering systems showed to be inadequate and incomplete. As such, a reliable durability assessment, based on measured properties, regarding the thermal mortars and also the system as a whole was performed. The numerical simulation proved to be a very useful and strong tool in the development of specific hygrothermal ageing adapted to different European climates.

The proposed durability assessment methodology was based on the following principles:

- Regarding the intrinsic properties and specific behaviour to water action of the thermal and finishing mortars, such as the capillary water absorption and solubility in water, it is possible to define if the system is suitable for interior or exterior application;

- Beyond the specific characteristics of the materials, the definition of the environmental conditions, such as the climatic zones, is a very important stage, since the application is adjusted to them;

- The identification of the main degradation mechanisms allowed defining representative ageing procedures of each climatic zone. The temperature and water action were observed as the main degradation agents related to freeze-thaw, temperature fluctuations and shrinkage degradation mechanisms;

- Both cold and moderate climates may be implemented by freeze-thaw and adapted heat-cold accelerated ageing cycles, while warm climate should also take into account the thermal shock by cold rain action in a hot façade. Regarding the high degradation of synthetic coatings to solar radiation, UV radiation must be used to perform the heating period; 
- The hygrothermal simulation and existing "in situ" data allowed optimizing the heat-cold and heat-rain ageing cycles to different climates, taking into account their climatic zone.

The heat-cold and heat rain cycles allowed the activation of the temperature fluctuation degradation mechanism and consequent cracking. In addition, the alteration of the porous structure of the matrix, by the water action, showed to be another relevant degradation mechanism. The freezing-thawing mechanism in thermal rendering systems requires further investigation and development.

The heat-cold cycle development and implementation enabled developing and optimizing specific heat-cold cycles to different European climates. The development of a theoretical algorithm regarding the heating and the cooling periods allowed the direct determination of the heat and cold cycle temperatures, based on the exterior air temperature of each climate.

The combination of all the referred aspects allowed developing a new durability assessment methodology that contributes to increase the knowledge on thermal mortars and related systems, especially regarding their durability performance, enhanced by the possibility of adaptation of the analysis to each climatic zone.

\section{ACKNOWLEDGEMENTS}

The first author would like to acknowledge the support of FCT - Fundação para a Ciência e a Tecnologia, the funding of the Doctoral Grant PD/BD/52659/2014, through the Doctoral Programme EcoCoRe. This work was financially supported by Project PTDC/ECICON/28766/2017 - POCI-01-0145-FEDER-028766 funded by FEDER funds through COMPETE2020 - Programa Operacional Competitividade e Internacionalização (POCI) and by national funds (PIDDAC) through FCT/MCTES and the Project Reuse - Rehabilitation and Sustainability, supported by LNEC. This work was financially supported by: 
UID/ECI/04708/2019- CONSTRUCT - Instituto de I\&D em Estruturas e Construções funded by national funds through the FCT/MCTES (PIDDAC). The authors also acknowledge to SaintGobain Weber, Secil Argamassas and Sival - Gessos Especiais to the materials supply.

\section{REFERENCES}

[1] ISO, ISO 15686 Buildings and constructed assets - Service life planning, in Part 1: General principles. 2000.

[2] ABCB, Durability in Buildings. Handbook. Guideline Document, ed. A.B.C. Board. 2006.

[3] Pinheiro, M.D., Environment and Sustainable Construction, ed. IST/DECivil. 2006, Amadora.

[4] ECEEE, Amending Directive 2010/31/EU on the energy performance of buildings and Directive 2012/27/EU on energy efficiency, D. 2018/844/EU, Editor. 2018, European Comission: Official Journal of the European Union.

[5] Veiga, M.d.R., Thermal insulation coatings for façades based on mortars: behaviour and quality evaluation, in Contribution of Mortars and ETICS to the Energy Efficiency of Buildings, T. 2010, Editor. 2010: Lisbon.

[6] Ferrándiz-Mas, V., et al., Lightweight mortars containing expanded polystyrene and paper sludge ash. Construction and Building Materials, 2014. 61: p. 285-292.

[7] Dylewski, R. and J. Adamczyk, The comparison of thermal insulation types of plaster with cement plaster. Journal of Cleaner Production, 2014. 83: p. 256-262.

[8] Brás, A., M. Leal, and P. Faria, Cement-cork mortars for thermal bridges correction. Comparison with cement-EPS mortars performance. Construction and Building Materials, 2013. 49: p. 315-327. 
[9] Maia, J., et al. Laboratory tests and potential of thermal insulation plasters. in Energy Procedia. 2015.

[10] Ibrahim, M., et al., Hygrothermal performance of exterior walls covered with aerogelbased insulating rendering. Energy and Buildings, 2014. 84: p. 241-251.

[11] Soares, A., et al., EN 998-1 performance requirements for thermal aerogel-based renders. Construction and Building Materials, 2018. 179: p. 453-460.

[12] Moussavi Nadoushani, Z.S., et al., Multi-criteria selection of façade systems based on sustainability criteria. Building and Environment, 2017. 121: p. 67-78.

[13] Gaspar, P.L. and J.d. Brito, Quantifying environmental effects on cement-rendered facades: A comparison between different degradation indicators. Building and Environment, 2008. 43(11): p. 1818-1828.

[14] Lewry, A. and L.F.E. Crewdson, Approaches to testing the durability of materials used in the construction and maintenance of buildings. Vol. 8. 1994. 211-222.

[15] Escobar, L.A. and W.Q. Meeker, A Review of Accelerated Test Models. Statist. Sci., 2006. 21(4): p. 552-577.

[16] Crowe, d. and A. Feinberg, "Concepts in Accelerated Testing" in Design for Reliability. Electronics Handbook Series, ed. J.C. Whitaker. 2001, Boca Raton, USA.

[17] Gonçalves da Silva, M., Influence of Environmental Aging on Properties of Polymeric Mortars. Journal of Materials in Civil Engineering, 2004. 16(5): p. 461-468.

[18] Ferrándiz-Mas, V. and E. García-Alcocel, Durability of expanded polystyrene mortars. Construction and Building Materials, 2013. 46: p. 175-182.

[19] Hannawi, K. and W. Prince-Agbodjan, Transfer behaviour and durability of cementitious mortars containing polycarbonate plastic wastes. European Journal of Environmental and Civil Engineering, 2015. 19(4): p. 467-481. 
[20] Daniotti, B., S.L. Spagnolo, and R. Paolini. Climatic Data Analysis to Define Accelerated Ageing for Reference Service Life Evaluation. in 11DBMC: 11th International Conference : Durability of Building Materials and Components. 2008. Istanbul, Turkey.

[21] EOTA, Assessment of working life of products, in Guidance Document 003. 1999, European Organisation for Technical Approvals: Brussels.

[22] Donatelli, A., et al. Durability and resistance to degradation of hemp fibres-based insulationg envelopes. in XIVDBMC: 14th International Conference on Durability of Building Materials and Components. 2017. Ghent, Belgium.

[23] CEN, EN 998 Specification for mortar for masonry, in Part 1: Rendering and plastering mortar. 2010, European Commitee for Standardization: Brussels.

[24] CEN, EN 1015 Methods of test for mortar for masonry, in Part 21: Determination of the compatibility of one-coat rendering mortars with substrates. 2002, European Commitee for Standardization: Brussels.

[25] EOTA, ETAG 004, in Guideline for European Technical Approval of External Thermal Insulation Composite Systems with Rendering. 2013, European Organisation for Technical Approvals: Brussels.

[26] Juaristi, M., T. Gómez-Acebo, and A. Monge-Barrio, Qualitative analysis of promising materials and technologies for the design and evaluation of Climate Adaptive Opaque Façades. Building and Environment, 2018. 144: p. 482-501.

[27] Perino, M. and V. Serra, Switching from static to adaptable and dynamic building envelopes: A paradigm shift for the energy efficiency in buildings. Vol. 3. 2015. 143163.

[28] Kottek, M., et al., World Map of the Köppen-Geiger climate classification updated. Meteorologische Zeitschrift, 2006. 15(No.3): p. 259-263. 
[29] Benmansour, N., et al., Thermal and mechanical performance of natural mortar reinforced with date palm fibers for use as insulating materials in building. Energy and Buildings, 2014. 81: p. 98-104.

[30] IBP, WUFI Pro, in WUFI Pro Manual, F.I. Bauphysik, Editor. 2016.

[31] LNEC, FE Pa 39 - Test Report of Wall Coatings, in Determination of water absorption under low pressure. 2002: Lisbon.

[32] CEN, EN 12504 Testing concrete in structures, in Part 4: Determination os ultrasonic pulse velocity. 2004, European Commitee for Standardization: Brussels.

[33] CEN, EN 1015 Methods of test for mortar for masonry, in Part 12: Determination of adhesive strength of hardened rendering and plastering mortars on substrates. 2000, European Commitee for Standardization: Brussels.

[34] CEN, EN 13497 Thermal insulation products for building applications in Determination of the resistance to impact of external termal insulation composite systems (ETICS). 2002, European Commitee for Standardization: Brussels.

[35] IPMA. Normais Climatológicas. 2019 [cited 201918 April]; Available from: https://www.ipma.pt/pt/oclima/normais.clima/.

[36] Sá, J., Durability of ETICS with high solar absorption in Civil. 2018, Faculty of Engineering of University of Porto: Porto.

[37] ISO, ISO 15927: Hygrothermal performance of buildings, in Calculation and presentation of climatic data. 2005, International Standard.

[38] Maia, J., N.M.M. Ramos, and R. Veiga, Evaluation of the hygrothermal properties of thermal rendering systems. Building and Environment, 2018. 144: p. 437-449.

[39] Ochs, H., J. Vogelsang, and G. Meyer, Enhanced surface roughness of organic coatings due to UV-degradation: an unknown source of EIS-artifacts. Progress in Organic Coatings, 2003. 46(3): p. 182-190. 
[40] Johnson, B.W. and R. McIntyre, Analysis of test methods for UV durability predictions of polymer coatings. Progress in Organic Coatings, 1996. 27(1): p. 95-106.

[41] LNEC, FE Pa 43 - Test Report of Wall Coatings, in Mechanical characteristics assessment by ultrassounds measurement. 2010: Lisboa.

[42] ASTM, C597 - 97, in Standard Test Method for Pulse Velocity Through Concrete. 1997, ASTM International: United States of America. 